\title{
INQUÉRITO DE FILARIOSE BANCROFTIANA EM SÃO LOURENÇO DA MATA - PERNAMBUCANO
}

\author{
James E. Dobbin Ir. * A Arquimedes E. Cruz *
}

Um inquérito epidemiológico foi realizado em Sấo Lourenço da Mata, Pernambuco, em dezembro de 1963, para determinar a prevalência da bancroftose. Este inquérito consistiu de: exame de sangue de uma amostra representativa da população humana, capturas e dessecacão de insetos transmissores.

Das 2459 pessoas examinadas (23.38\% da população estimada), 17 apresentavam microfilária de Wuchereria bancrofti. O indice de microfilaremia foi de $0.7 \%$.

Das 356 casas onde se realizou a captura de insetos, $79.77 \%$ foram positivas para Culex pipiens fatigans.

Dos 754 fatigans examinados para larvas de Wuchereria, $1.06 \%$ estavam infectados.

Em prosseguimento à execução do plano elaborado para a determinação da carta geográfica da Filariose bancroftiana em Pernambuco, teve-se a oportunidade de realizar, em dezembro de 1963, um inquérito epidemiológico para levantar os índices de infecção humana e culicidiana desta endemia, na cidade de São Lourenço da Mata.

A cidade de São Lourenço da Mata, sede administrativa do município do mesmo nome, faz parte do chamado grande Recife, e está situada no traçado da Rêde Ferroviária do Nordeste, a $17 \mathrm{~km}$ da capital do Estado. Pertence à zona fisiográfica litoral-mata. Suas coordenadas geográficas são as seguintes: 7.0 59' 4",6 de latitude sul e $35^{\circ}$ 02' 37',6 de longitude $W$. Gr., no rumo oes-noroeste.

Servida também por estrada pavimentada, possui tipos de clima Ams' e As', com predominância do primeiro. Quente e úmido com estação sêca compensada pelos to- tais elevados; chuvas de outono-inverno. A precipitação pluviométrica anual é estimada em $1200 \mathrm{~mm}$ e sua temperatura apresenta as seguinte $e_{S}$ médias: máxima $32^{\circ} \mathrm{C}$, mínimas $28^{\circ} \mathrm{C}$.

\section{MATERIAL E METODOS}

Para a execução da tarefa realizada, planejou-se examinar $25 \%$ da população humana de São Lourenço, que foi estimada em 10519 habitantes, pelo crescimento da população em progressão aritmética, tomando-se por base os censos de 1950 e 1960 do Instituto Brasileiro de Geografia e Estatística $(1958,1962)$.

A colheita de sangue era efetuada a domicílio, entre 19 e 23 horas, colhendo-se $20 \mathrm{~mm}^{3}$ de sangue de cada um dos moradores das casas visitadas, tomando-se o cuidado de, pela manhã, avisar do trabalho a ser realizado àquela noite, a fim de evitar, ao mínimo, as ausências e recusas, naturais em pesquisas desta natureza. 
Para atingir os percentuais desejados, em distribuição uniforme, seguiu-se a seguinte técnica de trabalho: uma casa sim e 3 casas não.

Efetuada a coleta de sangue, era o material examinado, no dia seguinte, após coloração pelo glicohemalumen de Caraz$z i$, processo tintorial que vèm sendo usado no Laboratório da Campanha contra a Filariose no Recife, e empregado por Dobbin Jr. \& Cruz (1967), nos inquéritos que realizaram em Pernambuco.

Para a determinação dos índices de infecção culicidiana, capturas domiciliąes mațtinas foram efetuadas entre 6 e 8 horas.

Os insetos capturados eram enviados ao Laboratório onde eram dessecados, 24 horas após a coleta.

\section{RESULTADOS E COMENTÁRIOS}

Os resultados das hemoscopias efetuadas estão discriminados nos quadros I e II, oncle os dados apurados por grupos etários e por sexo sạ̃o apresentados.

Da análise do quadro I, verifica-se que em São Louręnço da Mata, o índice de infecçāo humana por Wuchereria bancrofti é de $0.7 \%$.

Ainda do seu estudo, observa-se que o grupo etário de 10-14 anos foi o que forneceu maior contingente de infectados $(1.7 \%)$. Todos os outros tiveram taxas inferiores a $1 \%$, sendo que os grupos de menos de 1 ano e de 1-4 anos mostraram-se negativos aos exames.

\section{Q U A D R O I}

Distribuição dos percentuais de infecção por $W$. bancrofti, segundo os grupos etários na cidade de $\mathbf{S}$. Lourenço da Mata.

\begin{tabular}{r|r|r|r}
$\begin{array}{c}\text { Grupos } \\
\text { etários }\end{array}$ & $\begin{array}{c}\text { Exami- } \\
\text { nados }\end{array}$ & $\begin{array}{c}\text { Posi- } \\
\text { tivos }\end{array}$ & $\%$ \\
\hline-1 & 10 & 0 & - \\
$1--4$ & 269 & 0 & - \\
$5-9$ & 427 & 1 & 0.23 \\
$10-14$ & 352 & 6 & 1.70 \\
$15-19$ & 249 & 1 & 0.40 \\
$20-49$ & 852 & 7 & 0.82 \\
50 e + & 300 & 2 & 0.67 \\
TOTAIS & 2459 & 17 & 0.69
\end{tabular}

Q U A D R O I I

Distribuição por sexo dos examinados e dos positivos em São Lourenço da Mata

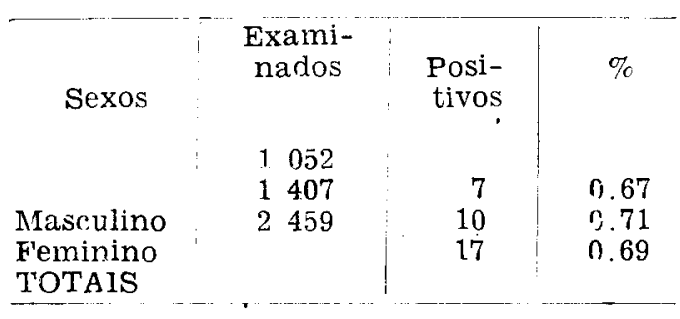

A distribuição por sexo, da população examinada e seus respectivo indices, estáo contidos no quadro II.

Neste quadro, observa-se que, em ambos os sexos, os índices de microfilaremia são pràticamente iguais, $0.67 \%$ para os masculinos e $0.71 \%$ para os femininos.

$\mathrm{O}_{\mathrm{S}}$ exames no grupo de menores de 1 ano foram realizados em número muito reduzido (10.) . Para isto, muito concorreram as recusas formais dos pais, não permitindo fôsse efetuada a coleta de sangue.

Durante êste inquérito foram visita tas na colheita de sangue 642 casas, e foram examinados $23.38 \%$ da população estimada, atingindo pràticamene, o número de exames previstos.

Os resultados obtidos na determinação dos índices culicidianos são apresentados no quadro III

As capturas domiciliares dos transmissores da $W$. bancrofti foram efetuadas em $356(55.45 \%)$ das moradias visitadas para a hemoscopia. Destas, sòmente foi possível capturar o Culex pipiens fatigans, único inseto existente na ocasião da coleta, em 284 delas, dando, pois, um índice domiciliário geral de $79.77 \%$.

Nas 284 casas que albergavam o Culex, foram capturados 1156 exemplares dêste culiníneo, dos quais 794 eram fêmeas $(68.69 \%)$ e 362 machos $(31.31 \%)$. Foi de 3.25 a densidade domiciliária.

Sòmente em 7 casas foram anotados insetos com formas evolutivas do verme.

Os resultados das hemoscopias realizadas, demonstraram que a Filariose bancroftiana, em São Lourenço da Mata, não constitui problema de saúde pública, embora exista transmissão local, comprovada pelo encontro de Culex infectados. 


\section{INOUÉRITO DE FILARIOSE EM \\ S. LOURENCO DA MATA \\ $-1963-$}

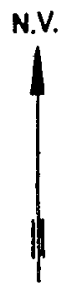

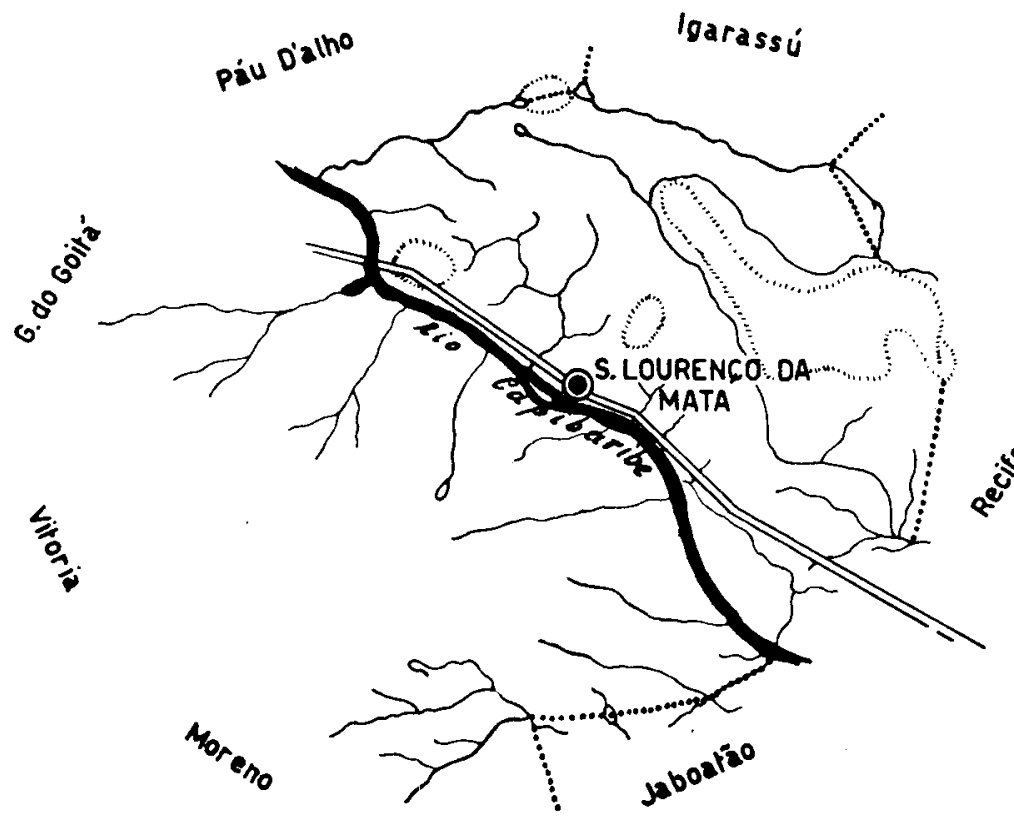

Averiguações que permitam demonstrar de transmissores infectados, e êste inquérito ter sido realizado há mais de 3 anos.

Um croquis do Município de São Lourenas condiçōes atuais da Endemia nesta localidade, são necessárias, face ao encontro ço da Mata é apresentado.

Indice domiciliário, densidade domiciliária e índice de infecçāo de Culex pipiens fatigans em S. Lourenço da Mata

\begin{tabular}{c|c|c|c|c|c|c}
\hline $\begin{array}{c}\text { N. } \\
\text { sas inspe- } \\
\text { cionadas }\end{array}$ & $\begin{array}{c}\text { N.o de ca- } \\
\text { sas com } \\
\text { Culex } p \\
\text { fatigans }\end{array}$ & $\begin{array}{c}\text { Indice } \\
\text { domici- } \\
\text { liário }\end{array}$ & $\begin{array}{c}\text { No de } \\
\text { Culex } \\
\text { captu- } \\
\text { rados }\end{array}$ & $\begin{array}{c}\text { Densi- } \\
\text { dade } \\
\text { domici- } \\
\text { liária }\end{array}$ & $\begin{array}{c}\text { N.o de } \\
\text { Culex } \\
\text { desse- } \\
\text { cados }\end{array}$ & $\begin{array}{c}\text { Indice } \\
\text { de in- } \\
\text { fecta- } \\
\text { dos }\end{array}$ \\
\hline 356 & 284 & 79.77 & 1156 & 3.25 & 754 & 1.06 \\
\hline
\end{tabular}




\section{$S U M M A R Y$}

An epidemiological survey was made in the city of São Lourenço da Mata, in Pernambuco, in december 1963, in order to evaluate the prevalence of bancroftiasis. The survey consisted of: a) blood examination of a representative sample of the human population; b) indoor captures of mosquitoes and c) dissection of these insects.

of 2459 examined person (23.38\%) of the population, $17(0.7 \%$ ) exhibited embryos of Wuchereria bancrofti, the only species of filaria found.

The blood sample, 20 cubic millimeters, were taken at night, between 7 to 11 p.m.

Of 356 houses scarched for mosquitoes, where blood samples were taken, $79.77 \%$, were positive for Culex pipiens fatigans The captures were made from 6 to 8 a.m.

Among 754 fatigans examined for filariae larvae, $1.06 \%$ harbored evolutive forms of $\mathrm{W}$. bancrofti.

\section{BIBLIOGRAFIA}

DOBBIN Jr., J.E. \& CRUZ, A.E. - Inquéritos de filariose em alguns municípios do litoral-mata de Pernambuco Rev. Brasil. Malariol. e Doen. Trop., 19: 45-51, 1967.

I.B.G.E. - Enciclopédia dos Municípios
Brasileiros. Estado de Pernambuco Vol. 18. Rio de Janeiro, 1958.

I.B.G.E. - VII Recenseamento Geral dc Brasil. Estado de Pernambuco, Sinopse preliminar do Censo Demográfico. Ric de Janeiro, 1962. 